Среди пациентов 1-й и 2-й групп мутации в ДНК МБТ составили соответственно: в гене гроB кодоне $531-48,3$ и $41,2 \%$, в кодоне 526 - 10,3 и 14,0\%, в гене $k a t G-60,3$ и $51,2 \%$. Характер мутаций в группах был одинаков. У пациентов в обеих группах преобладали мутации в 531-м кодоне гена гроB и в 315-м кодоне гена $k a t G$. Различия между группами по частоте встречаемости изолированных или сочетанных мутаций были статистически незначимыми. Частота одновременного выявления мутаций, обусловливающих устойчивость к рифампицину и изониазиду, у пациентов с ВИЧ-инфекцией составила $53,4 \%$, а у пациентов без ВИЧ-инфекции - $41,9 \%$.

Заключение. Анализ частоты и характера мутаций МБТ у больных туберкулезом с разным ВИЧ-статусом показал, что штаммы МБТ, одновременно имеющие мутации, обусловливающие устойчивость к рифампицину и изониазиду, чаще выделяются у пациентов с сочетанием ТБ/ВИЧ-и. Это связано с более бурным ростом МБТ, приводящим к быстрому накоплению мутаций в разных генах и увеличивающим вероятность появления штамма с множественной лекарственной устойчивостью. Качественных отличий по спектру мутаций у пациентов с разным ВИЧ-статусом не обнаружено. Вне зависимости от ВИЧ-статуса преобладали мутации, приводящие к высокому уровню устойчивости к основным препаратам первого ряда - рифампицину и изониазиду.

Веселова Елена Игоревна

(Elena I. Veselova)

E-mail:drveselovae@mail.ru (якУТия)

Винокурова М. К., Петрова О. Д., Кондаков С. Н., Кравченко А. Ф.

ГБУ РС (Я) Научно-практический центр «Фтизиатрия», г. Якутск, РФ

\title{
RESULTS OF IMPROVEMENT OF DIAGNOSTICS AND TREATMENT OF MULTIPLE DRUG RESISTANT TUBERCULOSIS IN THE THE REPUBLIC OF SAKHA (YAKUTIA)
}

\author{
Vinokurova M. K., Petrova O. D., Kondakov S. N., Kravchenko A. F.
}

Scientific Practical Phthisiology Center, Yakutsk, Russia

Цель исследования: определить эффективность лечения туберкулеза с множественной лекарственной устойчивостью (МЛУ-ТБ) при внедрении инновационных технологий диагностики и современного подхода к назначению режимов химиотерапии.

Материал и методы. Проведен анализ исходов лечения по четвертому (IV) режиму химиотерапии у больных МЛУ-ТБ в годовой когорте 2015 г. (247 больных) по данным республиканского противотуберкулезного диспансерного отделения ГБУ РС (Я) НПЦ «Фтизиатрия». Для обследования этой когорты использовали молекулярно-генетические методы (МГМ) диагностики туберкулеза «АНК-32» ПЦР-РВ (Синтол, Россия) и GeneXpert MTB/RIF (Cepheid, США). Бактериологическую диагностику проводили на жидких и твердых питательных средах.

Результаты исследований. В годовой когорте МЛУ-ТБ всего зарегистрировано 247 человек по группам: впервые выявленные - 70 (28,3\%); рецидив - 15 (6,1\%); после неэффективного кур- са - 109 (44,1\%); после прерывания - 14 (5,7\%); прочие - $39(15,8 \%)$. В результате изменения тактики диагностики и ведения больных с МЛУ-ТБ и достаточного обеспечения диагностическими и лекарственными средствами когорта 2015 г. в 1,5 раза превышала когорту предшествующего года (всего 164 человека), особенно по зарегистрированным случаям после предыдущего неэффективного исхода - 109 (2014 г. - 54 человека) и впервые выявленным - 70 (2014 г. - 55 человек).

IV стандартный режим назначен 32 (13,0\%) пациентам, из них по МГМ у 10 определена лекарственная устойчивость (ЛУ) как минимум к рифампицину, остальным 22 режим назначен с учетом высокого риска МЛУ-ТБ и с имеющимися данными на контактных лиц. Распределение по группам регистрации: впервые выявленные - 24 (75\%), рецидив $5(15,6 \%)$, после неэффективного курса - 1 (3,1\%), прочие - 2 (6,3\%).

IV индивидуализированный режим назначен 215 (87,0\%) пациентам по результатам определения лекарственной чувствительности на жидких 
и твердых средах. По группам регистрации преобладают случаи после неэффективного курса 108 (50,2\%), впервые выявленные - 46 (21,4\%), прочие - 37 (17,2\%), после прерывания - 14 (6,5\%), рецидив - 10 (4,7\%). Среди 56 случаев впервые выявленных и рецидивов у 44 (78,6\%) ранее по МГМ была определена ЛУ к изониазиду и рифампицину в сочетании или как минимум к рифампицину и назначен IV стандартный режим. При получении результатов на жидких средах в ускоренные сроки пациентам проводилась индивидуализация режима с учетом лекарственной чувствительности к противотуберкулезным препаратам.

Через 24 мес. лечения в годовой когорте эффективный исход химиотерапии достигнут у 63,2\% пациентов, неудача определена в 13,4\% случаев, умерли от туберкулеза 6,1\%, прервали лечение 5,2\%, выбыли за пределы 6,5\% и продолжают лечение свыше 24 мес. 1,6\% пациентов с МЛУ-ТБ. По группам регистрации более высокие показатели эффективности химиотерапии достигнуты среди впервые выявленных - 75,7\%, а также среди зарегистрированных на повторные курсы после неэффективных исходов - 68,5\%.

При этом у 22 пациентов, зарегистрированных на IV стандартный режим с учетом высокого риска МЛУ-ТБ, но неподтвержденной ЛУ как минимум к рифампицину, эффективный исход химиотерапии определен в 89,5\% в группе впервые выявленных и у единственного случая с рецидивом. У 10 человек, закончивших лечение по стандартному IV режиму с ЛУ как минимум к рифампицину, эффективный исход определен среди впервые выявленных в 40,0\% случаев, среди рецидивов - в 25,0\%. Неудача определена у единственного случая из группы «прочие» и в 75,0\% случаев с рецидивом туберкулеза. Исход «умершие» среди данных групп не зарегистрирован, есть случаи исходов «выбыли за пределы республики».

Из 215 пациентов, зарегистрированных на индивидуализированный IV режим, эффективного исхода химиотерапии удалось достигнуть при впервые выявленном МЛУ-ТБ в 73,9\% случаев, среди рецидивов - 40,0\%, после неэффективного курса $68,5 \%$, у ранее прервавших лечение - 35,7\%, среди прочих - 48,7\%. Неудачный исход наиболее часто определяется в группе «прочие» $-27,1 \%$, а также среди рецидивов - 20,0\%, среди впервые выявленных составляет 10,9\%, в группе пациентов из ранее неэффективных курсов - 7,4\%. Умерли от туберкулеза по группам: после предыдущих неэффективных исходов - 8,3\%; после прерывания - 14,3\%; из группы «прочие» - 5,4\%; впервые выявленные 4,3\%. Наиболее часто повторный курс прерывают пациенты, зарегистрированные с уже установленными ранее фактами прерывания предшествующих курсов лечения $(35,7 \%)$ и с наличием в анамнезе ранее неэффективных исходов (4,6\%). Имеются случаи исходов «выбыли за пределы республики» и продолжают лечение более 24 мес. единичные пациенты, с новым случаем - 2,2\%, с повторным курсом $-2,8 \%$.

При подробном анализе случаев определения неэффективного исхода у большинства пациентов (от 54,5 до 100\%) определены медико-социальные отягощающие факторы: отсутствие работы, жилья, семьи и родственных связей; наличие зависимостей и инвалидности, сопутствующих заболеваний; в анамнезе длительное наблюдение, предыдущие неудачи и отрывы от лечения, хронические деструктивные формы туберкулеза с МЛУ к 5 и более противотуберкулезным препаратам; предшествующее пребывание в УФСИН отмечено в $24,2 \%$ случаев.

Заключение. В Республике Саха (Якутия) в результате внедрения современных технологий диагностики и химиотерапии достигнуты повышение частоты выявления и увеличение числа своевременно зарегистрированных на лечение с МЛУ-ТБ среди пациентов с впервые выявленным туберкулезом легких и с рецидивом. Рациональное использование противотуберкулезных препаратов позволило значительно увеличить группу больных, зарегистрированных на повторные курсы химиотерапии. Быстрая диагностика и современные режимы химиотерапии при МЛУ-ТБ повышают эффективность лечения всех больных, особенно впервые выявленных и зарегистрированных на повторные курсы после предыдущих неудач.

\section{Винокурова Мария Константиновна (Maria K. Vinokurova) \\ E-mail:mkvin61@mail.ru}

